\title{
Article
}

\section{Post-match video-based feedback: A longitudinal work-based coach development program stimulating changes in coaches' knowledge and understanding}

Raya-Castellano, Pablo E, Reeves, Matthew, Fradua-Uriondo, Luis and McRobert, Allistair P

Available at http://clok.uclan.ac.uk/38167/

Raya-Castellano, Pablo E, Reeves, Matthew ORCID: 0000-0002-3903-2910, Fradua-Uriondo, Luis and McRobert, Allistair P (2021) Post-match video-based feedback: A longitudinal work-based coach development program stimulating changes in coaches' knowledge and understanding. International Journal of Sports Science \& Coaching, 16 (6). pp. 1259-1270. ISSN 1747-9541

It is advisable to refer to the publisher's version if you intend to cite from the work. http://dx.doi.org/10.1177/17479541211017276

For more information about UCLan's research in this area go to http://www.uclan.ac.uk/researchgroups/ and search for <name of research Group>.

For information about Research generally at UCLan please go to http://www.uclan.ac.uk/research/

All outputs in CLoK are protected by Intellectual Property Rights law, including Copyright law. Copyright, IPR and Moral Rights for the works on this site are retained by the individual authors and/or other copyright owners. Terms and conditions for use of this material are defined in the policies page. 


\section{Post-match video-based feedback: A longitudinal work-based coach}

\section{2 development program stimulating changes in coaches' knowledge and}

\section{3 understanding}

\section{Abstract}

5 The literature regarding formal coach education and development highlights issues of

6 transference of usable knowledge to the real-world context. This study sought to engage

7 coaches from a Spanish football academy in a longitudinal work-based coach

8 development program (CDP) focused on the delivery of post-match feedback. The CDP

9 was delivered over a 23-month period through collaboration between a sport pedagogue

10 researcher-practitioner, the Academy Management Team, and an experienced research

11 team. The study adopted a case study design, utilizing a multiple method data collection strategy that occurred in several stages: 1) Systematic observations (Sep-Dec 2018) and

2) debrief (Jan 2019), where baseline coach behaviors and underpinning knowledge were recorded; 3) a workshop and a directed task (Mar 2019), encouraging coaches to apply new knowledge; 4) a directed task 2 and reflective interview (Apr/May 2019), facilitating coaches' reflection on their past deliveries and rationalization and planning of their forthcoming sessions' delivery and 5) a consolidation interview (Apr 2020), capturing knowledge stabilization. Qualitative data suggest that there was an increased understanding in the adoption of behaviors including corrective feedback, silence, questioning, and player participation throughout the CDP. In addition, coaches' self-

21 reflection found acceptance of their coaching delivery or a disconnect between their desired and actual behaviors during the delivery of video-based feedback. This study provides a preliminary framework for further implementation and exploration in

24 developing coaches' knowledge and understanding of delivering post-match video-based feedback. 
26 Key words: coach education; coaching behaviors; knowledge development; post-match.

27

28 
Coach development programs (CDP) have received considerable attention in recent years for their perceived impact on coaching practice. ${ }^{1}$ It has been suggested that coaches learn through formal (i.e., accredited courses), non-formal (i.e., workshops, talks, etc.), and informal (i.e., day-to-day coaching, observations or discussions with other practitioners) modalities, ${ }^{2}$ although these rarely occur in isolation. ${ }^{3}$ Whilst formalized CDPs have been criticized for being too theoretically driven and de-contextualized from practice, the informal mode is suggested to be more effective for coach learning., ${ }^{4,5}$ However, the effectiveness of CDPs has often been claimed by showing behavior change at post-intervention stages. ${ }^{6}$

The impact that formal CDPs have on coaches' development has been questioned because these events result in limited changes of knowledge and behavior. ${ }^{7,8}$ For example, Stodter \& Cushion ${ }^{9}$ examined the development of two coaches after participating in a National Federation's 'Youth Coaching Module'. Their findings suggested coaches' rejection of new concepts due to incompatibility with previous knowledge or lack of application within their contexts. Similarly, Stodter and Cushion ${ }^{6}$ compared the learning of coaches in a formal coach education group and a group of coaches who did not take part in any CDP. Coaches in the education group demonstrated increased understanding of the use of questioning and whole-part-whole structures, though this translated to minimal changes of behavior. It was suggested that the ineffectiveness of this CDP might be due to coaches' utilization of different approaches without critical consideration of

50 their implications. Therefore, coaches appear to relay on behaviors that have previously worked, not necessarily meeting their players' needs. 
54 the sub-conscious to conscious level. ${ }^{11}$ Thus, examination of behavioral data, video-based

55 feedback, and peer conversations have been employed to facilitate reflective practice of 56 youth coaches from different sports. ${ }^{12,13,14}$ Nonetheless, coaches appear to merely 57 describe their plans and intentions without questioning its validity (i.e., single-loop 58 learning $)^{14}$ rather than comparing their ideas and reasoning about coaching against their 59 actual behaviors and underlying rationales (i.e., double-loop learning). ${ }^{15}$

60 CDP implemented by National Governing Bodies (NGBs) has been compared to a process of indoctrination and control ${ }^{4,16}$. For example, coach developers working for the NGB and supporting youth coaches in their clubs have been shown to adapt the meaning of 'player-centered' in their interest to dominate coaches ${ }^{8}$. In contrast, Cope et al. ${ }^{17}$ found that an unaffiliated coach educator empowering coaches and assisting them with reflective conversations enhanced their experience. Furthermore, positive changes (i.e., reduction of technical practices, direct management, feedback and convergent questioning; increase of total questioning) were reported although might not exclusively relate to the intervention due to the multiple variables surrounding applied coaching environments and 'out of practice' activities coaches engage in on a daily basis. Hence,

70 it is suggested that in-club visits from independent coach developers empowering and caring for learners might be more appropriate for developing coaches. delivered within pitch-based scenarios. Although contemporary learning frameworks

74 (i.e., ecological dynamics, skill acquisition, and constructivist learning theory) advocate 75 for less prescriptive approaches, ${ }^{20,21,22}$ studies have continually identified coaches' frequent use of 'instruction' and 'feedback'. ${ }^{23,24,25}$ Video-based feedback (VBF) sessions

77 have typically been studied qualitatively to understand perceptions of factors influencing 78 its delivery, ${ }^{26,27}$ with a growing preference for balanced positive and negative sequences 
of video, ${ }^{26}$ active participation of players ${ }^{28}$ and cautious use of individual feedback. ${ }^{29}$

80 Only one study has systematically observed team-based VBF sessions at a youth academy

81 with coaches most utilized behavior being feedback ${ }^{25}$, and no examples were identified

82 of studies that have attempted to develop coaches in the delivery of post-match VBF

83 sessions. Therefore, combining objective and subjective data ${ }^{30}$, the current study aimed

84 to investigate changes in coaches' knowledge and understanding during a longitudinal

85 CDP, developed and delivered by a sport pedagogue researcher-practitioner.

86

87 Method

\section{Research context}

This study was conducted at the academy of a club competing at the Spanish La

90 Liga 123. The academy comprised eleven teams (under 9 to under 19) all playing in competitive leagues. The Academy Manager and Head of Methodology were responsible for the development of coaches and the coaching curriculum, which did not include content regarding VBF sessions. They identified coach communication as an important developmental area amongst their coaches and welcomed a sport pedagogue (henceforth referred to as A1) and research team in assisting the club.

To encourage coaches to embrace this new department, the sport pedagogue was

97 invited to several events and meetings and was introduced to all academy staff, with reference to his experience working at other European academies. The Academy Manager

99 continually highlighted the importance of communication in coaching and the CDP

100 actions A1 would be undertaking. It was emphasized that all interactions between 101 participants and the sport pedagogue would be confidential. 

withdrew, expressing difficulties in communicating whilst being recorded. This coach's team had experienced a poor run of form and faced relegation; something that within the Spanish academy system would have been detrimental to the who academy. As a result, only two coaches participated in this study. Both Pedro and Juan (pseudonyms), who worked with the under 9 and 13 age-groups, completed the full CDP. Their pen pictures are presented below (Table 1).

[INSERT TABLE 1 HERE]

\section{Procedure}

Prior to data collection, ethical approval was received from a university ethics

114 committee; coaches were informed about the purpose of the study and provided signed

115 informed consent before the study commenced.

116 All competitive fixtures were filmed by volunteers, and coaches prepared VBF to

117 be delivered in the dressing room before the subsequent training session. The sport 118 pedagogue took field notes after each session that enabled engagement in reflective and 119 reflexive dialogue ${ }^{31}$ with the research team.

120 Coaches in this small-scale, in-depth case study CDP were purposively sampled 121 based on 1) their limited experience delivering VBF sessions, 2) plenty opportunities for 122 observation, and 3) the AMT's perceived positive attitude towards their development.

123 The CDP, and associated data collection, occurred in several stages: 1) Systematic 124 observations (Sep-Dec 2018); 2) debrief (Jan 2019); 3) workshop and directed task (Mar 125 2019); 4) directed task two and reflective interview (Apr/May 2019); and 5) consolidation interview (Apr 2020). 
130 The lead coach and players met in the changing room up to three days after the

131 previous game and delivered VBF sessions with post-match purposes. Twelve sessions

132 were filmed using a digital video camera (Sony HDR-CX900E, China) mounted on a

133 tripod, and ensuring the projector screen and all players were visible. The first session for

134 each coach was used to familiarize coaches and players ${ }^{32}$ and was omitted from final

135 analyses. Each coach was then filmed over an 11 -week period $\left(1^{\text {st }}\right.$ of October to $17^{\text {th }}$ of

136 December 2018), with a total of ten post-match team-based VBF sessions analyzed. Thus,

137 five sessions for each coach (average duration: Pedro, $11.33 \pm 2.60$ minutes; and Juan,

$13825.13 \pm 4.79$ minutes) were used to define coaches' baseline behaviors.

139 As there are no validated systematic observation tools to analyze coach behavior

140 within this context, we followed procedures adopted elsewhere ${ }^{25}$. To ensure

141 appropriateness of the instrument for this specific study, continuous consultation occurred

142 between $\mathrm{A} 1$ and the research team. A familiarization session for each coach was pilot

143 coded to explore the coaches' behaviors using the modified instrument. This enabled the

144 research team to identify the behaviors across each session prior to inclusion/exclusion

145 from the final behavior categories (Table 2).

\section{[INSERT TABLE 2 HERE]}

All sessions were coded with Sportscode $\odot$ Gamebreaker (version 10) and exported to Microsoft Excel 2010. This generated a frequency count and duration for

149 every behavior within each session. Mean frequency count and percentage time were

150 calculated by dividing the sum of every behavior's count within each session by the five sessions delivered by each coach. Duration data were converted into seconds, and mean 
153 by the five sessions. Mean percentage times were calculated dividing the mean duration 154 of each independent behavior by the sum duration of behaviors and multiplied by 100 . Intra- and inter-observer reliability for frequency data were calculated with the

156 formula (agreements/ agreements + disagreements) x 100. Duration data were converted

157 into seconds before utilizing the formula. Intra-observer reliability was checked by A1

158 who coded the same session twice after bouts of five sessions. Verification achieved 92\%

159 and 90\% agreement for frequency and duration data, respectively. Inter-observer

160 reliability was calculated comparing A1 and a trained observer's same session codes.

161 Agreement achieved was $88 \%$ and $87 \%$ for frequency and duration data, respectively.

162 Both reliability checks obtained lower scores (between 2 and 11\%) than the achieved by

163 Ford et $\mathrm{al}^{24}$, but still exceeded the accepted $85 \%$ reliability threshold. ${ }^{33}$

Debrief

Debrief interviews were conducted with participants to explore their thoughts and

167 experiences of their sessions without knowing their behavioral profiles. These were

168 intended to elucidate Pedro and Juan's beliefs, knowledge, and understanding on the

169 influence of coach behaviors on player learning and development. In particular, we were

170 keen to examine their use of questioning and silence as pedagogical tools in this specific

171 context and how this might transfer into training sessions (Table 3). These behaviors have

172 been highlighted for facilitating players' cognitive engagement ${ }^{24,25}$.

[INSERT TABLE 3 HERE]

174 Workshop \& directed task

175 On the $4^{\text {th }}$ of March 2019, both coaches attended a workshop within an office in

176 the club's training ground, where research findings applied to coaching were presented.

177 This was prepared between A1 and the Academy Management Team and leaded by A1 
178 who encouraged frequent input from coaches about the specific aspects addressed. The

179 Head of Methodology was present during the entire 50-minute workshop and assisted A1

180 by asking him questions regarding the theoretical frameworks presented or emphasizing

181 A1 points. Both A1 and the Head of Methodology remained neutral without providing

182 practical guidelines regarding how to behave during post-match VBF sessions.

183 Firstly, the workshop introduced the behaviors observed during the post-match

184 VBF sessions and presented the ideas from Williams and Hodges, ${ }^{21}$ regarding the utility

185 of prescriptive frequent and immediate feedback, compared to reduced and delayed

186 feedback, whilst exploring additional contributory factors (i.e., bandwidth feedback and

187 questioning). Questioning was then discussed as a behavior for stimulating implicit

188 learning and linked to the use of silence for enabling players thinking and answering. ${ }^{34}$

189 Likewise, convergent and divergent questions were defined as questions restricting or

190 broadening the possible response options, ${ }^{35}$ without suggestion of which one is more

191 beneficial or when to adopt them within VBF sessions. The workshop concluded by

192 asking coaches to consider when, where, and how they incorporated questions into their

193 feedback process during VBF. Coaches then delivered two VBF sessions after the

194 workshop which provided an opportunity for implementing ideas.

Directed task 2 \& reflective interview

197 Coaches were given a breakdown of their behaviors three days before the

198 reflective interview. To facilitate that coaches could identify consistencies or

199 inconsistencies between their actual and desired behaviors, previous self-reflection on

200 their data was allowed. The reflective interview schedule explored: 1) recall of behaviors

201 and its definitions; 2) biographical and demographic questions; 3) coaches' perceptions

202 of their behavioral data; 4) questions examining the alignment between current and 
desired behaviors; and 5) questions to ascertain their intended behaviors' organization

204 within particular clips. If required, video clip examples (i.e., stimulated recall) were

205 shown, followed by a general open question and a subsequent question aiming that

206 coaches rationalized their actions. ${ }^{36}$

Consolidation interview

After reflective interviews, there was no contact with the coaches regarding their

210 VBF sessions. The second season, coaches were encouraged to implement what they had

211 learnt within their new contexts (see table 1 for group and role details). To determine the

212 extent to which participants' knowledge and understanding had stabilized and changed, a

213 final consolidation interview was conducted with each coach.

Debrief, reflective, and consolidation interviews of coaches averaged 21 minutes

24 seconds $\pm 1.37,44$ minutes 20.5 seconds \pm 5.5 , and 70 minutes 25.5 seconds \pm 2.9 ; and yielded 6, 16 and 23 single-line-spaced pages of text, respectively. Interviews were

217 transcribed verbatim and A1 read transcripts several times during the analysis phase to

218 ensure familiarity with the data. ${ }^{37}$ In-depth analysis was conducted using thematic

219 analysis procedures. ${ }^{38}$ This process started deductively with inspection of the predetermined themes followed by line-by-line examination of each transcript to identify

221 further emerging themes. ${ }^{39}$ To consider changes between interviews, a matrix of concepts

222 was generated that included initial concepts, categories, and subcategories. Concepts

223 were deemed to have been modified when qualitatively different or more frequently used. ${ }^{40}$ Rigor in the process was maintained through frequent discussions amongst the research team who critiqued the analytic decisions of A1 until agreement on thematic

226 structure, names, descriptions, and meaning of themes was achieved (Figure 1). 
228

229

230

231

\section{Results, findings and discussion}

\section{Phase 1: Systematic observation \& debrief}

Systematic observations and debrief suggested varied initial patterns of behavior (table 4) and levels of knowledge and awareness during coaches' VBF sessions.

\section{[INSERT TABLE 4]}

Pedro's most employed behavior was 'feedback'; normally positive, though corrective statements lasted longer. These were interspersed with shorter bouts of silence and a marginally greater number of divergent questions; which might suggest why players contributed to discussion for almost the same amount of time that Pedro provided feedback. Furthermore, qualitative data reflected Pedro's intention to use as much positive feedback as possible, and his preference for open questioning as a mechanism to extend the response options, and to encourage player engagement in higher-order thinking. However, he seemed unsure about how and why his questioning was more convergent during training compared to during VBF sessions. Moreover, Pedro used silence for $17.9 \%$ of the session, though he was not conscious of why and when he was being silent:

Pedro: “... I think during training I do more closed questions compared to video sessions.

A1: Why do you think you do that?

Pedro: Eh...good question [smiling]...It's a different coach's attitude. The video is more relaxed and the other [training] you want to rise up the tempo. So that there aren't many stops and maybe you give more direct feedback.

A1: $\quad$ When does it make sense being silent within video sessions?

Pedro: I have never thought about that...I believe silence doesn't make sense within a video session. You are showing something and if you don't give any feedback or if they answer and you don't tell them anything, it doesn't make sense". 
256 half (25.4\%) being corrective. He demonstrated frequent, but short, spells of silence and

257 a dominant use of convergent questions, that appeared to facilitate limited player 258 participation. In his debrief interview Juan's awareness of utilizing these behaviors was 259 ascribed this to his players adapting to a new game format. Conversely, when asked about 260 his use of questioning types alongside his silence, he demonstrated a lack of awareness of his observed behaviors:

"I use more open questions, I think...It's trying to get them to see and assess the possibilities or choose other options such as the other side, switch it, turn, etcetera. I would try more open, to see if they're able to interpret the different options they have in that play... During video sessions, I don't normally do silence. I always try to explain with images a little bit more. As I have the opportunity to show and they watch themselves on video, I prefer not to...". particular question, he suggested: "If it's an open question, I would directly tell them the different options...because perhaps there are situations they cannot interpret, and I can".

275 focused on the effects that specific coach behaviors have upon players. While individual 276 VBF sessions include more positive feedback than negative, ${ }^{41}$ data from this study 277 highlighted preferences toward positive and corrective feedback approaches. Previous 278 studies have found that combinations of negative and corrective feedback can facilitate 279 learners' correction of errors when their task performance is not appropriate. ${ }^{42}$ Thus, VBF 280 sessions have the opportunity to enhance players' confidence ${ }^{26}$ whilst also identifying areas for further development. However, a recipient's openness to receive feedback in 
282 front of their peers should be considered, especially if highlighting specific improvable 283 aspects of the game. ${ }^{29}$

284 Coach questioning practices have, typically, been shown to stimulate players' low 285 order thinking, and often answered by the coach. ${ }^{18,34}$ Divergent questions are suggested 286 to encourage individuals to engage in higher order thinking and, thus, generate more 287 sophisticated responses and new knowledge. ${ }^{35}$ Pedro exhibited a tendency toward 288 divergent questions, whereas Juan demonstrated higher propensity for convergent 289 questioning. Interestingly, in a similar study Raya-Castellano et al., ${ }^{25}$ found that all 290 coaches utilized greater convergent questions. However, Mason, Farrow and Hattie ${ }^{41}$ 291 reported higher levels of divergent questioning being employed by elite Australian

292 Football coaches during individual post-match VBF sessions, though this might be 293 attributable to the age and phase of development differences between the two samples. In this study, coaches' actual and desired feedback were in agreement, though participants demonstrated limited knowledge and awareness surrounding their use of 296 questioning or silence. This supports the epistemological gap reported in literature 297 between behavior and underpinning knowledge. ${ }^{43}$ In Juan's case, there appeared to be a 298 difference between his ideas of what, when, and how to use questioning and his actual use of questioning. ${ }^{15}$ Furthermore, both coaches were not aware of why they chose to be silent when they did during their VBF sessions. This might reflect their limited experience delivering VBF sessions, or a broader lack of understanding around pedagogic principles.

Phase 2: Reflective interview

Feedback

Pedro maintained his preference for being positive to avoid potential negative 306 influence upon player confidence, although he also explained that this depended on 
307 players' previous performance and the difficulty of the upcoming fixture. In addition, he

308 believed corrective feedback was more effective than negative feedback and this could

309 be used either within positive or negative clips:

"I think the corrective...is the most useful because you're providing the boy with solutions to his problems... and even to things they do well, you're giving them a wider variety of alternatives. As an example, he has done well because he got passed a rival, but within another game, he had a teammate, and the defender is gonna be better. He's gonna continue trying dribbling and he's not gonna win the duel. And maybe he could have done a 2 v 1 . So he knows he has other alternatives".

Juan was appreciative of his balanced positive and negative feedback and appeared more considered in the use of the latter not being as constructive as corrective feedback: "...I don't like dedicating much to this is wrong, don't do that, no. I'd tell him that the best option was the other. I wouldn't tell him not to do it...I prefer showing him another alternative that I think is better... That without emphasizing whether is good or bad". deteriorating players' confidence. ${ }^{44}$ Participants suggested that inclusion of corrective feedback can manipulate the message provided by a positive or negative video clip and feedback. For both coaches, corrective feedback was more constructive than negative feedback. Pedro suggested that this could be used within positive or negative clips to either propose further alternatives or make corrections. Nonetheless, it is yet to be

330 examined the extent to which players develop their knowledge and/or retain feedback

331 when receiving different combinations of game sequences and feedback. Only Mason et $332 \mathrm{al}^{41}$ have examined player recall of coaches' feedback one week after an individual post333 match VBF session and there is a dearth of quasi-experimental studies in this area. 334 Therefore, providing alternatives to positive and negative game situations might expand 
335 players' knowledge, though consideration must be given to the time and type of

336 information, ensuring it is congruent with their learning and playing ability.

Silence

Coaches have previously shown lack of understanding of their silence during training. ${ }^{18,43}$ However, long periods of silence used deliberately can empower players to engage in the problem-solving process. ${ }^{19}$ After this CDP, Pedro demonstrated increased awareness in his use of silence and outlined two main instances within his VBF sessions where he did so for the benefit of players. He expressed the rationale for silence after questioning but doubted if his silence while players observed clips was the most effective approach for maintaining under nine players' concentration on the footage: "Regarding silence after my questions, you've got to leave them to be protagonist. So, they get to the solution and are able to see, in that play, what is happening...Perhaps, while we're watching the video, I've got to give less silence because it's twenty seconds. So none gets distracted, to keep their attention... in the play, in what is happening”.

Similarly, contradictions between his actual and desired silence values seemed to objectives. Apart from being more aware of its application, he contemplated silence as an alternative to maintain concentration on the footage with a potential question to be answered after: “...maybe I should use [silence] a bit more... Telling them to watch this play or watch these three plays and after we'll discuss them... I think seeing that I am gonna ask them a question...I think that it helps focus their concentration more and so they see where they might have failed".

Juan presented more periods of silence, though these accounted for a smaller total percentage duration compared to Pedro (table 4). To maintain player observation of the 
363 clips; Juan was considering longer silences prior to questions, whereas Pedro seemed

364 willing to reduce his silence as an alternative. This could be due to the attention span and

365 cognitive capacity of the under nine's, which might be a factor influencing the delivery

366 of VBF sessions. ${ }^{27}$

367 Further, at this stage only Pedro was conscious of silence after questions being

368 important to allow players to think and answer. In their analysis of coach questioning

369 practices during training sessions, Cope et $\mathrm{al}^{34}$ found no more than two seconds of post-

370 question silence and after these frames, responses were provided by the coach. Therefore,

371 future studies specific to the VBF context could monitor coaches' silences after their

372 questions and/or the impact that shorter and larger silences might have on the quality of

373 learners' cognitions, responses and knowledge development.

Questioning and player participation

Pedro proposed questioning as a potential tool for encouraging his under nine's player thinking, curiosity, and participation. When shown a sequence of his sessions

where he was re-questioning a player's response with a second question, he stated:

Pedro: "It's the same question, isn't? Don't know what I'd be thinking...but maybe I have formulated the question and that's why he has answered to something I didn't want him to respond. Then, I formulate it [the question] again differently.

A1: What is your objective for doing this?

Pedro: In order to get into what I want them to see in the video. To concrete the final response, but that this is given by them.

A1: Could the coach give the information after a wrong response from the player?

Pedro: Yes, I could but at these ages within these video sessions, I prefer that they get to the result or the solutions instead of me telling them".

convergent and divergent questions to the coach's desired response options: 
"Regarding convergent and divergent, as age increases, maybe the divergent need to increase and convergent decrease. With my group, maybe I need to guide them myself with more concrete questions".

Juan also believed questioning and player participation were useful for encouraging players' autonomous thinking. When players were unable to answer a question, a second question could be formulated to ensure the players generated the response. Additionally, Juan was able to define the concepts of convergent and divergent questioning, but unable to articulate how to combine them within sessions. When shown a session clip, he described his approach of stopping the footage and divergently asking players to explore the existing alternatives at that instance. “...I would try to turn it around to simplify a bit the response or if I see they're not able to [respond]; trying to turn it around to see if from other side, they find the solution and not give it myself straight away. Obviously, if there isn't a way for them to get the response, then maybe I tell them, but I would ask it differently first...Perhaps, before the action happens, stop the play and ask the player involved the options he sees. With the convergent, ...it's much simpler for them to answer if I stop the clip".

Both coaches expressed their desire to use divergent questions to enable players'

417 Juan's data reflects greater use of convergent questioning that he linked to his reduced

418 player participation. Furthermore, coaches declared that combinations of questions could be used to tease out their own desired responses from the players, which suggest that they 
positioned themselves as knowledge gatekeepers. ${ }^{45}$ Questions can be probing, stimulating

421 the recall of knowledge and the development of new understandings; or guiding, which can direct players towards responses. ${ }^{46}$ Open-ended questions combined with VBF have been shown to develop greater tactical knowledge (i.e., number of self-regulatory concepts and a more sophisticated concept structure) for youth players in an experimental group compared to a control group. ${ }^{47}$ When not well formulated or cueing the desired response, questions might encourage players' convergent thinking, which constraints the exploration of further possibilities of response not predetermined by the coach. This is not to say that coaches should avoid the use of convergent questions. As Pedro suggested, if players do not possess sufficient knowledge to answer a divergent question, a more convergent question could reduce the challenge initially posed. Thus, divergent and convergent questions might be combined to encourage players to generate answers; drawing on existing knowledge whilst enabling new knowledge development.

\section{Behavior acceptance or rejection}

Coaches described the same order in which they planned to sequence their behaviors to favor players' learning. This consisted of silence for player observation being ensued by a divergent question, player participation and coach feedback or a convergent question if player responses had not concreted the coach's pursued response. When asked about his opinion on his current data and whether he was willing to make any future behavior modifications, Pedro indicated: enough...The more the player participates, the better. Because I do a good number of divergent and I use convergent when the boys don't respond to what I am looking for.". 
In contrast, Juan was rejecting his delivery and aimed to increase his silence,

446 player participation and re-arranging the order in which his behaviors occurred during 447 particular clips:

448

451

452 453

"Thinking what I said about silence, it seems to me a very good idea...telling them to watch in silence. They would concentrate more and think about the options. But here [feedback], I would have to reduce the time compared to what I wished...First that they become aware whether what they've done is wrong or what other options they had. It would have to come out from them. And afterwards, I can reinforce what they've said".

Reflection on their own behavior data provoked different responses for coaches. Pedro was satisfied with his behavior profile, whereas Juan had found behavioral 'disturbances ${ }^{14}$ that contradicted his desired behaviors. Because of these discoveries, he was planning to reduce his feedback and redistribute the sequence of behaviors within clips. ${ }^{48}$ Therefore, behavioral statistics from coaches' post-match VBF either confirmed or encouraged changes to their desired delivery approach and can be employed with monitoring purposes so coaches self-assess the alignment between their intentions and actual behaviors.

This CDP comprised a workshop and two directed tasks intending to stimulate reflection about coaches' previous sessions and how they might implement content from the workshop within their post-match VBF. This appeared to assist coaches in deciding how to approach future sessions and determine clear expectations that their sessions should include that are better tailored to player benefit. Nevertheless, the mixed-method design of this study does not demonstrate causality between the CDP activities employed (i.e., workshop and directed tasks) and the outcomes achieved in terms of coaches' knowledge development. 
His knowledge seemed stabilized eleven months after the reflective interview took

474 place with minor changes in the meaning of a few themes. When asked about his behavior profile, he maintained his satisfaction, albeit showed a will to reduce negative feedback even more due to its disadvantages for players. Moreover, Pedro was considering the player as an active cognitive agent much more. Although he seemed willing to interrupt silence with cues, so players concentrated on the footage at the reflective interview; he was now more conscious of enabling players' observing the game without directing players' attention to certain aspects: game it doesn't work but it might do it in the following game. If from such an early age you constrain them, they will play with fear to do. Therefore, you've got to try they don't feel the pressure of I'm not doing this because he said that is bad".

"During the clip, because I don't want to condition them on that particular player. I wanted them to be self-sufficient and focus on what they thought".

player comments that differed to his clip's objective, if these 'fitted' his understanding: “...what do you see in this play? The boys see things that you hadn't seen. If I see it's interesting, I guide them and explore where do we get with their responses and my questions... But if they answer useless responses for their learning, I use more convergent to facilitate and guide them to what I was looking for within that clip".

Juan

Comparisons between Juan's reflective and consolidation interviews revealed very little changes in themes' meaning. Juan maintained his belief of divergent questioning facilitating player thinking and proposed planning starting divergent 
500 difficulties under thirteen players could have generating elaborated responses in front of

501 teammates and had decided further options if players were unable to answer a question:

502

503

504

505

506

507

508

509

510

511

512

513

514

515

516

517

518

519

520

521

522

523

Juan: "...at these ages, although questions are divergent, the boys don't always reason enough or are too shy many times. A question that requires a longer response, they shorten it a lot...It's difficult.

A1: $\quad$ What could you do to overcome this difficulty?

Juan: ...Maybe continue asking questions towards where I want to get. Try to guide them with two or three more convergent questions to where I want to get...or even the participation of a third player to encourage him to take part or to see if they get into any kind of agreement".

Finally, opposed to the reflective phase, Juan had found alternative approaches to combine divergent and convergent questions during his VBF sessions:

"Perhaps asking the options he has at that instance and once he has seen the clip, asking a convergent where he gives his opinion on whether is right or wrong and propose other alternatives... there are questions that need more thinking. Often what you want is right, you've given me the response, but now I want you to identify the why. So they think a little bit more".

Coaches' knowledge seemed stabilized and enhanced from reflective to consolidation interview. Stodter and $\mathrm{Cushion}^{49}$ argue that realistic opportunities are required to transfer new knowledge into behaviors within their contexts because concepts are linked to the situations where they are learnt. Thereby, it could be argued that coaches' knowledge settled after eleven months of no contact with A1 and the Academy Management Team due to having reflected and attempted to implement knowledge within their particular post-match VBF sessions. Hence, CDPs focused on a particular situationspecific coaching task involving self-reflection and application of CDP content might aid coaches to consolidate their knowledge in the medium term. Nevertheless, future quasiexperimental studies could corroborate this assumption. 


\section{Limitations}

531 While this research extends literature in the areas of coach behaviour and coach

532 education, it also presented some limitations. Firstly, it is difficult to establish causal

533 relationships between the CDP activities and their impact on coaches, because of the

534 absence of a control group not undertaking any education. Moreover, the quality of

535 coaches' reflection during the second directed task could have been enhanced by

536 incorporating players' anonymous perceptions about their coaches' delivery.

\section{Conclusion}

This bespoke longitudinal work-based CDP constitutes an in-depth exploration of

540 changes in knowledge and understanding achieved by two coaches with varied

541 backgrounds ${ }^{50}$ and working with different age-groups. Their varied baseline levels of

542 knowledge appeared to increase and stabilize as the CDP progressed. In addition, this

543 study extends our understanding of the delivery of VBF in junior-elite football and how

544 behaviours can be utilised to fulfil the post-match session objectives.

545 This research also provides various practical considerations for coaches and coach

546 development practice. In particular, a broad framework for structuring a long-term

547 approach to developing coaches, in relation to a specific issue to bring about positive

548 change in coaches' practice. Indeed, coaches in this study appeared to develop knowledge

549 and awareness during the CDP; particularly due to the clear opportunities to implement

550 ideas and reflect on their delivery. The examination of behavior data either reinforced

551 coaches' delivery or enhanced their willingness to change. This suggests that a bespoke

552 CDP, comprising multiple learning mechanisms and integrated opportunities for

553 reflection; delivered and supported longitudinally can be an effective approach for coach

554 development in an applied football environment. 


\section{References}

556 1. Allison W, Abraham A and Cale A. Advances in coach education and development: From research to practice. London: Routledge, 2016.

2. Lyle J and Cushion CJ. Sports coaching concepts: A framework for coaches ' practice. Oxon: Routledge, 2017.

3. Colley $\mathrm{H}$, Hodkinson $\mathrm{P}$ and Malcolm J. Informality and formality in learning: $A$ report for the learning Skills Research Centre. London: Learning and Skills Research Centre, 2003.

4. Cushion CJ and Nelson L. Coach education and learning: developing the field. In: P Potrac, W Gilbert and J Denison (eds) Routledge handbook of sports coaching. Oxon: Routledge, 2013, pp. 359-374.

5. Mesquita I, Ribeiro J, Santos S, et al. Coach learning and coach education: Portuguese expert coaches' perspective. Sport Psychol 2014; 28: 124-136.

6. Stodter A and Cushion CJ. Evidencing the impact of coaches' learning: changes in coaching knowledge and practice over time. J Sports Sci 2019; 2086-2093. Available from: https://doi.org/10.1080/02640414.2019.1621045

7. Nelson LJ and Cushion CJ. Reflection in coach education: The case of the national governing body coaching certificate. Sport psychol 2006; 20: 174-183.

8. Cushion JC, Griffiths M and Armour K. Professional coach educator in-situ: a social analysis of practice. Sport Educ Soc 2017; 533-546. Available from: https://doi.org/10.1080/13573322.2017.1411795

9. Stodter A and Cushion CJ. Coaches' learning and education: a case study of cultures in conflict. Sports Coach Rev 2014; 3: 63-79.

10. Gilbert W and Trudel P. Learning to coach through experience: Reflection in model youth sport coaches. J Teach Phys Educ 2001; 21: 16-34. 
580 11. Cushion CJ. Reflection and reflective practice discourses in coaching: a critical analysis. Sport Educ Soc 2016; 82-94. Available from: https://doi.org/10.1080/13573322.2016.1142961

12. Partington M, Cushion CJ, Cope E, et al. The impact of video feedback on

584 professional youth football coaches' reflection and practice behaviour: A longitudinal 585 investigation of behaviour change. Reflect Pract 2015; 16: 700-716.

586 13. Wardsworth N, Charnock L, Russell J, et al. Use of video-analysis feedback within a six-month coach education program at a professional football club. J Sport Psychol Action 2018 ; 73-91.

Available from: https://doi.org/10.1080/21520704.2018.1528324

590 14. Voldby CR and Klein-DФssing R. "I thought we were supposed to learn how to become better coaches": developing coach education through action research. Educ Action Res 2019; 534-553. Available from: https://doi.org/10.1080/09650792.2019.1605920

594 15. Argyris C and Schön DA. Theory in Practice: Increasing professional effectiveness. $595 \quad$ San Francisco, CA: Jossey-Bass, 1974.

16. Griffiths MA, Armour $\mathrm{K}$ and Cushion CJ. Trying to get our message across: 597 Successes and challenges in an evidence-based professional development programme 598 for sport coaches. Sport Educ Soc 2016; 283-295. Available from: $599 \quad$ https://doi.org/10.1080/13573322.2016.1182014

600 17. Cope E, Cushion CJ, Harvey S, et al. Investigating the impact of a Freirean informed 601 coach education programme. Phys Educ Sport Pedagogy 2020; 1-14. Available from: $602 \quad$ https://doi.org/10.1080/17408989.2020.1800619 
603 18. Partington M, Cushion CJ and Harvey S. An investigation of the effect of athletes'

604 age on the coaching behaviours of professional top-level youth soccer coaches. $J$ $605 \quad$ Sports Sci 2014; 32: 403-414.

606 19. Smith M and Cushion C. An investigation of the in-game behaviours of professional, $607 \quad$ top-level youth soccer coaches. J Sports Sci 2006; 24: 355-366.

608 20. Otte F, Davids K, Millar S, et al. When and how to provide feedback and instructions 609 to athletes? - How Sport Psychology and Pedagogy insights can improve coaching 610 interventions to enhance self-regulation in training. Front Psychol 2020; 11: 1-14.

611 21. Williams AM and Hodges NJ. Practice, instruction and skill acquisition in soccer: $612 \quad$ Challenging tradition. J Sports Sci 2005; 23: 637-650.

613 22. Light R. Complex learning theory - Its epistemology and its assumptions about 614 learning: Implications for physical education. J Teach Phys Educ 2008; 27: 21-37.

23. Partington $\mathrm{M}$ and Cushion CJ. Performance during performance: Using Goffman to understand the behaviours of elite youth football coaches during games. Sports Coach Rev 2012; 1: 93-105.

24. Ford P, Yates I and Williams M. An analysis of practice activities and instructional behaviours used by youth soccer coaches during practice: Exploring the link between

25. Raya-Castellano PE, Reeves MJ, Littlewood M, et al. An exploratory investigation of junior-elite football coaches' behaviours during video-based feedback sessions. Int $J$ Perform Anal Sport 2020; 20: 729-746.

26. Groom R, Cushion CJ and Nelson L. The delivery of video-based performance analysis by England youth soccer coaches: Towards a grounded theory. J Appl Sport 
627 27. Middlemas S and Harwood C. No place to hide: Football players' and coaches'

628 perceptions of the psychological factors influencing video feedback. J Appl Sport $629 \quad$ Psychol 2018; 30: 23-44.

630 28. Wright C, Carling C, Lawlor C, et al. Elite football player engagement with 631 performance analysis. Int J Perform Anal Sport 2016; 16: 1007-1032.

632 29. Nelson L, Potrac P and Groom R. Receiving video-based feedback in elite ice633 hockey: A player's perspective. Sport Educ Soc 2014; 19: 19-40.

634 30. Dugdale JH, Sanders D, Myers T, et al. A case study comparison of objective and 635 subjective evaluation methods of physical qualities in youth soccer players. $J$ Sports 636 Sci 2020; 38: 1304-1312. Available from:

$637 \quad$ https://doi.org/10.1080/02640414.2020.1766177

638 31. Attia M and Edge L. Be(com)ing a reflexive researcher: A developmental approach 639 to research. Open Rev Educ Res 2017, 4: 33-45.

640 32. Darst PW, Zakrajsek DB and Mancini VH. Analysing physical education and sport 641 instruction (2nd ed.). Champaign, IL.: Human Kinetics, 1989.

642 33. van der Mars H. Observer reliability: Issues and procedures. In: P Darst, D Zakrajsek 643 and V Mancini (eds) Analysing physical education and sport instruction. Champaign, 644 IL.: Human Kinetics, 1989, pp.53-80.

645 34. Cope E, Partington M, Cushion, CJ, et al. An investigation of professional top-level 646 youth football coaches' questioning practice. Qual Res Sport Exerc Health 2016; 8: $647 \quad 380-393$.

648 35. Harvey S and Light R. Questioning for learning in game-based approaches to teaching 649 and coaching. Asia-Pacific J Health Sport Phys Ed 2015; 6: 175-190. 
650 36. Applebee AN, Langer JA, Nystrand M, et al. Discussion-based approaches to 651 developing understanding: classroom instruction and student performance in middle and high school English. Am Educ Res J 2003; 40: 685-730.

37. Braun V, Clarke V and Weate P. Using thematic analysis in sport and exercise research. In: B Smith and AC Sparkes (eds) Routledge handbook of qualitative research in sport and exercise. Oxon: Routledge, 2016, pp.191-205.

38. Hanton S and Jones G. The acquisition and development of cognitive skills and strategies: I. Making the butterflies fly in formation. Sport Psychol 1999; 13: 1-21.

39. Scanlan TK, Ravizza K and Stein, GL. An in-depth study of former elite figure skaters: I. Introduction to the project. J Sport Exerc Psychol 1989; 11: 54-64.

40. Saldaña J. Longitudinal qualitative research: Analysing change through time. Oxford: Altamira Press, 2003.

41. Mason RJ, Farrow D and Hattie J. An exploratory investigation into the reception of 663 verbal and video feedback provided to players in an Australian Football League club. Int J Sports Sci Coach 2020; 1-11. Available from:

\section{https://doi.org/10.1177/1747954120951080}

42. Tzetzis G, Votsis E and Kourtessis T. The effect of different corrective feedback 667 methods on the outcome and self-confidence of young athletes. J Sports Sci Med 2008, 7: 371-378.

43. Partington M and Cushion CJ. An investigation of the practice activities and coaching behaviours of professional top-level youth soccer coaches. Scand J Med Sci Sport 2013; 23: 374-382.

44. Groom R and Cushion CJ. Using of video based coaching with players: A case study. Int J Perform Anal Sport 2005; 5: 40-46. 
674 45. Potrac P and Cassidy T. The Coach as a 'More Capable Other'. In: RL Jones (ed) The 675 Sports Coach as Educator: Re-Conceptualising Sports Coaching. Oxon: Routledge, $676 \quad$ 2006, pp. 39-50.

677 46. Sahin A. Teachers' classroom questions. Sc Sci Math 2007; 107: 369-370.

678 47. García-González L, Moreno MP, Moreno A, et al. Effectiveness of a video-feedback 679 and questioning programme to develop cognitive expertise in sport. PloS One 2013, 680 8: e82270-12. Available from: https://doi.org/10.1371/journal.pone.0082270

681 48. Jarvis P. Learning to be a person in society. Oxon: Routledge, 2009.

682 49. Stodter A and Cushion C. What works in coach learning, how and for whom? A 683 grounded process of soccer coaches' professional learning. Qual Res Sport Exerc $684 \quad$ Health 2017; 9: 321-338.

685 50. Agustí D, Ballester R, Juan-Blay J, et al. The academic background of youth soccer 686 coaches modulates their behavior during training. Front Psychol 2020; 1-11. 687 Available from: https://doi.org/10.3389/fpsyg.2020.582209 